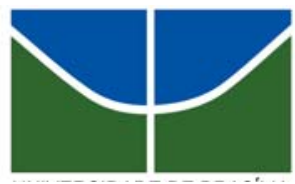

UNIVERSIDADE DE BRASÍLIA

Centro de Excelência em Turismo

Pós-graduação Lato Sensu

Curso de Especialização em Qualidade em Alimentos - V

\title{
A contaminação de alimentos gordurosos através da migração de plastificantes do tipo DEHA e DEHP do filme PVC
}

\author{
Sumara Teixeira Alves
}

Orientadora: Profa . Dra . Rita de Cássia Coelho de

Almeida Akutsu 


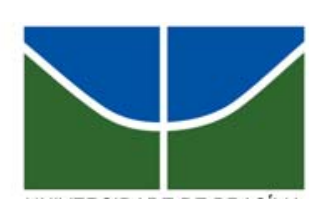

UNIVERSIDADE DE BRASÍLIA

Centro de Excelência em Turismo

Pós-graduação Lato Sensu

Curso de Especialização em Qualidade em Alimentos - V

\title{
A contaminação de alimentos gordurosos através da migração de plastificantes do tipo DEHA e DEHP do filme PVC
}

\author{
Sumara Teixeira Alves \\ Orientadora: Profa . Dra . Rita de Cássia Coelho de \\ Almeida Akutsu \\ Monografia apresentada ao Centro de Excelência \\ em Turismo - CET, da Universidade de Brasília - \\ UnB, como requisito parcial à obtenção do grau de \\ Especialista em Qualidade em Alimentos - V
}

Brasília - 2009 
Alves, Sumara Teixeira.

A contaminação de alimentos gordurosos através da migração de plastificantes do tipo DEHA e DEHP do filme PVC / Sumara Teixeira Alves - Brasília, 2005.

$x i, 43$ f.: il.

Monografia de Especialização apresentada ao curso Qualidade em Alimentos/ Centro de Excelência em Turismo/ Universidade de Brasília, Brasília, 2009.

Orientador: Profa. Dra Rita de Cássia Coelho de Almeida Akutsu

1. Embalagem de alimentos. 2. Plastificantes. 3. Ftalatos.

4. Adipatos 


\section{UNIVERSIDADE DE BRASÍLIA Centro de Excelência em Turismo \\ Pós-graduação Lato Sensu \\ Curso de Especialização em Qualidade em Alimentos - V}

\section{Sumara Teixeira Alves}

\section{Aprovado por:}

Professor orientador: Dra ${ }^{\mathrm{a}}$. Rita de Cássia Coelho de Almeida Akutsu

Professor: MSc. Luis Antonio Borgo

Professor: MSc. Lívia de Lacerda de Oliveira Pineli

Brasília, 23 de março de 2009. 
Dedico esse trabalho a minha mãe, Alaydes da Rocha Mendes. Norteadora da minha formação e do meu caráter. 


\section{AGRADECIMENTOS}

A Deus, pelo que Ele representa em mim.

À Professora Doutora Rita de Cássia Coelho de Almeida Akutsu, orientadora e incentivadora deste trabalho. Agradeço pela paciência e compreensão nas horas difíceis, e pela oportunidade de receber seus conhecimentos.

À Laura Lyra, minha co-orientadora, dedicada, compreensiva e amiga. Muito obrigada pela oportunidade de ter você me co-orientando e assim poder compartilhar da sua sabedoria e experiência. Sua presença segura e competência estão presentes nas sugestões e críticas apresentadas.

Aos meus colegas da pós-graduação pela convivência neste período da minha vida e pela oportunidade de compartilhar conhecimentos

Aos professores do Centro de Excelência em Turismo e da Universidade de Brasília, pela dedicação em nos passar seus conhecimentos e experiências.

Aos funcionários do Centro de Excelência em Turismo, que tanto nos ajudaram.

À minha família que me ajuda incondicionalmente, especialmente a Simone e a Soraya.

Aos meus amigos pela convivência, pelos conselhos e palavras de estímulo. 


\section{RESUMO}

As embalagens de plásticos facilitam sobremaneira a vida das pessoas, mas nas embalagens, como os filmes de policloreto de vinila (PVC), pode ocorrer migração de componentes da embalagem para o produto. Essas substâncias, chamadas de migrantes, são aditivos que podem causar contaminação toxicológica e sensorial ao produto. Nos filmes de PVC destinados para alimentos são incorporados plastificantes, como o ftalato de di-(2-etilhexila) (DEHP) e/ou o adipato de di-(2etilhexila) (DEHA), compostos orgânicos, usados para conferir ao filme flexibilidade. Contudo, quando este se encontra em contato direto com o alimento, o plastificante pode migrar do filme de PVC para o gênero alimentício, pois não estão permanentemente ligados ao material plástico, podendo se tornar indevido ao alimento, contaminando o mesmo. Vários autores revisados indicam que os aditivos DEHP e o DEHA estão diretamente ligados a efeitos tóxicos, como doenças hepáticas e problemas na fertilidade. A Agência Nacional de Vigilância Sanitária (ANVISA) regulamentou na Resolução de Diretoria Colegiada RDC n 17/2008, uma lista positiva para os aditivos para materiais plásticos destinados em contato com alimentos. Neste sentido, o objetivo deste trabalho foi identificar as embalagens de filme de PVC utilizadas para acondicionar alimentos gordurosos, utilizados pelas redes de hipermercados e supermercados do Plano Piloto - Brasília, Distrito Federal. A pesquisa foi desenvolvida nos estabelecimentos visitados e por meio de investigação na rede de internet. As informações obtidas das redes de hipermercados e supermercados e das empresas fabricantes de filme de PVC foram discutidas embasadas na lei de proteção ao consumidor. Com os resultados, podese fazer uma avaliação da exposição dos consumidores a estes plastificantes.

Palavras-chave: embalagem para alimentos, plastificantes, ftalatos, adipatos 


\begin{abstract}
Plastic packaging are seen as key products to help on food storage, but in these packs, just as PVC films, plastic' components can migrate from the packaging material to the food product. Such substances are aditives that can cause toxic and sensory contamination to the food product. In PVC films composition there are added plastifiers such as ftalato de di-(2-etilhexila) (DEHP) or adipato di-(2-etilhexila) (DEHA), organic compounds used to improve the plastic flexibility. However, whenever it gets in touch with food, the plastifier can migrate from the packaging material to the food, once it is not strongly bounded to the plastic material. Many authors describe that DEHP and DEHA are intimately related to the toxic effects that can cause liver cancer and fertility problems, for example. Brazil's National Agency of Sanitary Regulation - ANVISA - selected a list of pakcaging materials that can get in touch with food and set up a resolution, RDC 17/2008. This way, this study objective was to investigate the adequacy of the sanitary legislation for plastic aditives in PCV films, which are not allowed to get in contact with high fat level food, used by the market and supermarket stores located at Plano Piloto - Brasília, Federal District. The results should evaluate the costumers' exposition to these plastifiers.
\end{abstract}

Keywords: food packs, plastifier, ftalato de di-(2-etilhexila) (DEHP), adipato di-(2etilhexila) (DEHA) 


\section{LISTA DE ILUSTRAÇÕES}

Figura 1 - Alimentos embalados com filme de PVC. .........................................

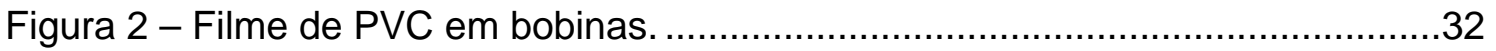

Quadro 1 - Hipermercados e supermercados e suas quantidades na regiao do Plano

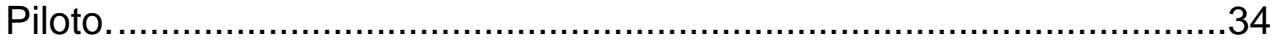




\section{LISTA DE ABREVIATURAS E SIGLAS}

ABIFICC: Associação Brasileira de Instituições Filantrópicas de Combate ao Câncer ANVISA: Agência Nacional de Vigilância Sanitária

BPF: Boas Práticas de Fabricação

DEHA: Adipato de di-(2-etil-hexila)

DEHP: Ftalato de di-(2-etil-hexila)

FDA: Food and Drug Administration

FIOCRUZ: Fundação Oswaldo Cruz

INCQS: Instituto Nacional de Controle de Qualidade em Saúde

IUPAC: International Union of Pure and Applied Chemistry/União Internacional de Química pura e Aplicada

LME: Limite de Migração Específica

MERCOSUL: Mercado Comum do Sul

MVC: Monômero Cloreto de Vinila

$\mathrm{NaCl}$ : Cloreto de Sódio

OMS: Organização Mundial de Saúde

PVC: Policloreto de Vinila

RDC: Resolução de Diretoria Colegiada

SAC: Serviço de Atendimento ao Consumidor 


\section{SUMÁRIO}

INTRUDUÇÃO 12

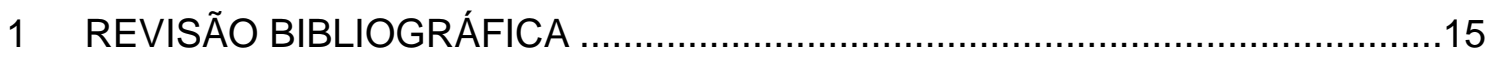

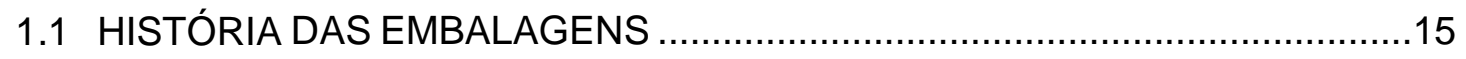

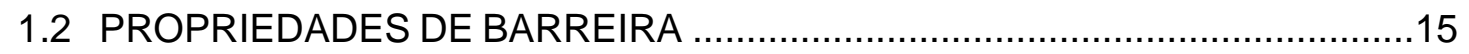

1.3 EMBALAGENS PLÁSTICAS DE ALIMENTOS .............................................17

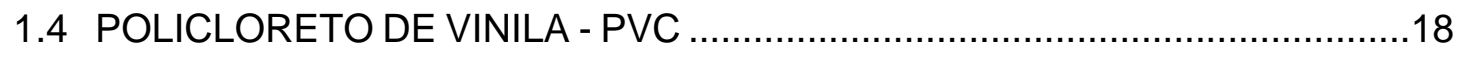

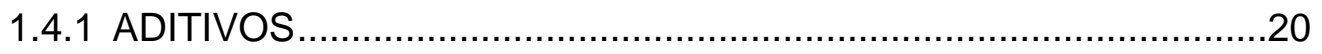

1.4.1.1 PLASTIFICANTES USADOS EM PVC …………..................21

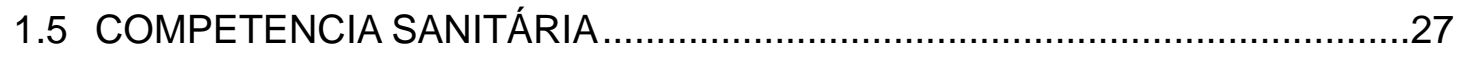

1.5.1 LEGISLAÇÕES PARA EMBALAGEM DE ALIMENTOS ..................28

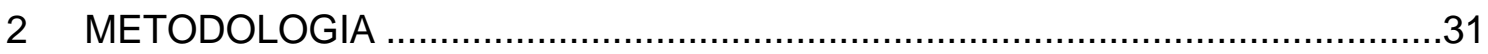

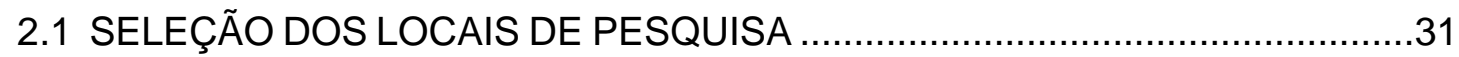

2.2 IDENTIFICAÇÃO DOS ALIMENTOS QUE USAM FILME PVC ….....................31

2.3. IDENTIFICAÇÃO DOS TIPOS DE FILMES DE PVC ......................................32

2.4. LEITURA E AVERIGUAÇÃO DOS FILMES DE PVC ......................................32

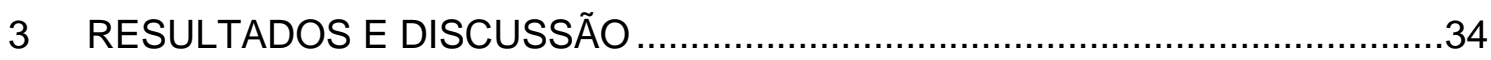

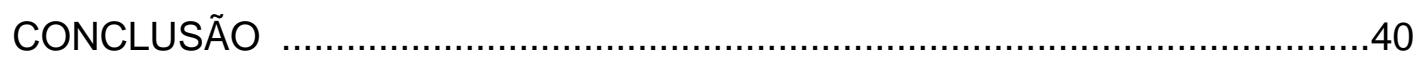

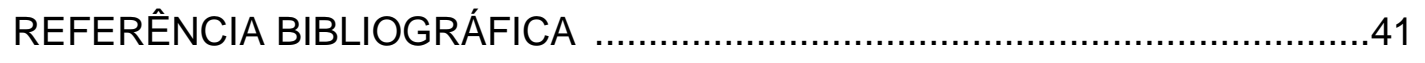




\section{INTRODUÇÃO}

$\mathrm{Na}$ sociedade moderna, a mulher está cada vez mais conquistando seu espaço no ambiente profissional e participando das mudanças ocorridas na contemporaneidade. Aos poucos as habilidades e características femininas começam a ser valorizadas pela sociedade, deixando a mulher, dessa forma, de ser uma mera coadjuvante em determinados segmentos sociais e profissionais possibilitando, assim, mais o seu acesso às posições estratégicas em suas profissões.

$\mathrm{Na}$ sociedade atual, a mulher vem aprendendo a lidar com os problemas e conseguindo, aos poucos, saber discernir e superar as dificuldades encontradas na dupla, e algumas vezes, na tripla jornada de trabalho, no lar e fora dele. As mulheres vêm ao longo dos anos participando na construção de uma sociedade mais justa, de um mundo melhor e mais equilibrado, no qual se desenha um novo papel para a mulher moderna.

O ingresso da mulher no mundo do trabalho alterou a rotina familiar, e conseqüentemente, o modo de interagir com os membros de uma mesma economia doméstica. Para superar essa incômoda ausência das donas-de-casa ocasionada pela transição no comportamento da sociedade, toda ela sofreu adaptações e buscou soluções para amenizar seus efeitos. A evolução dos eletrodomésticos, criados para facilitar a "vida moderna", trouxe consigo o aumento do consumo e a descartabilidade, fatos que transformaram os espaços compartilhados na habitação e até mesmo os relacionamentos. Além disso, as novas tecnologias dos materiais trouxeram a mudança das embalagens, tecidos mais práticos e objetos em materiais plásticos, originando uma série interminável de produtos alternativos. Essa proliferação de dispositivos facilitadores marcou uma verdadeira revolução na rotina das famílias, alterando papéis antes tão arraigados e mudando comportamentos.

Neste sentido, os produtos de policloreto de vinila (PVC) têm importante papel na qualidade de vida da sociedade moderna, pois são destinados a diferentes setores das indústrias com excelente relação custo/benefício, em áreas como a construção civil, e a alimentação.

Por sua versatilidade, as embalagens plásticas têm sido amplamente utilizadas na indústria alimentícia. As embalagens de alimentos têm como principal 
função proteger o produto da contaminação externa, porém, a possibilidade de que ocorra contaminação do produto por constituintes da própria embalagem não pode ser desconsiderada, principalmente por estar diretamente relacionada com a saúde humana, considerando, dessa forma, a segurança alimentar e a qualidade dos alimentos (MELO, 2007).

A Agência Nacional de Vigilância Sanitária (ANVISA) regulamentou na Resolução RDC n017, de 17 de março de 2008, os aditivos, como os plastificantes, que podem ser utilizados na produção de embalagens plásticas que entrarão em contato direto com produtos alimentícios, assim como suas concentrações e limites de migração permitidos, de forma a não afetar a saúde do consumidor.

Os plastificantes mais comuns utilizados nos filmes comerciais de PVC são o ftalato de di-(2-etil-hexila) (DEHP) e o adipato de di-(2-etil-hexila) (DEHA). De acordo com Souza, Corio e Temperini, (2003), estes plastificantes podem migrar da matriz polimérica para o usuário a partir do consumo de alimentos gordurosos embalados com esses filmes. Essa possibilidade de migração de compostos da embalagem pode comprometer a resistência química e mecânica do material e também acarretar conseqüências toxicológicas ao consumidor (MELO, 2007).

Estudos de toxicidade e epidemiológicos em países como Japão, Reino Unido e Estados Unidos documentaram a migração destes plastificantes para os alimentos em contato com os filmes de PVC. $E$,além disso, a toxicidade destes em animais experimentais foi comprovada em várias pesquisas. (MELO, 2007; SOUZA, CORIO, TEMPERINI, 2003; e ESTEVES et al. (2006)

O grande consumo de alimentos embalados com filme de PVC gerou a necessidade de investigar se o uso dessa embalagem está de acordo com a legislação sanitária correspondente de regulação da utilização de aditivos nas embalagens de filme de PVC, que podem causar danos a saúde humana pela migração de plastificantes para alimentos gordurosos tornando, assim, uma questão de saúde publica. Como não foram encontradas pesquisas com esse tipo de abordagem na região do Distrito Federal, o objetivo deste trabalho foi identificar as embalagens de PVC, em bobina, utilizadas para acondicionar alimentos gordurosos como queijo mussarela, presunto, carne in natura e embutidos, em hipermercados e supermercados de Brasília. 
Os objetivos específicos foram: identificar as bobinas de filme de PVC que são utilizados nos estabelecimentos selecionados, verificar as embalagens em que as bobinas de filme de PVC estão acondicionadas e identificar se há a presença da composição química nas embalagens de filme de PVC e se essas estão em conformidade com a Resolução RDC n 17/2008 da ANVISA.

Para uma melhor estruturação, o conteúdo deste trabalho foi dividido em introdução, três capítulos e conclusão. A introdução apresenta a contextualização deste trabalho embasada numa sintética revisão da literatura sobre o PVC e seu uso na indústria alimentícia.

No Capítulo 1, há uma visão panorâmica acerca das abordagens sobre as embalagens plásticas que entram em contato com alimentos, como o PVC. É comentado sobre sua história, sobre a propriedade de barreira das embalagens, 0 uso de plastificantes no PVC e sua toxicidade, assim como sua migração para alimentos gordurosos e a legislação vigente para esses aditivos.

O Capítulo 2 apresenta a metodologia desenvolvida na pesquisa. Como foi realizada a seleção dos estabelecimentos em que o filme de PVC, em bobinas, era comercializado, a identificação dos alimentos gordurosos acondicionados neste tipo de embalagem, se as embalagens em que as bobinas eram acondicionadas apresentavam a composição química dos mesmos.

Os resultados e as discussões estão apresentados no Capítulo 3, onde serão analisadas as informações obtidas das redes de hipermercados e supermercados e das empresas fabricantes dos filmes de PVC. Essas informações foram discutidas a luz da Lei nº 8.078 de Proteção ao Consumidor (BRASIL, 1990).

Na Conclusão, são apresentadas as considerações finais e limitações desta pesquisa. 


\section{REVISÃO BIBLIOGRÁFICA}

\subsection{HISTÓRIA DAS EMBALAGENS}

O conceito de embalagem como recipiente para o armazenamento de alimentos surgiu há mais de 10.000 anos. Estudiosos, como Aléxis Davis, autor de "História da Embalagem", acreditam que o início da embalagem foi no século XVI quando se tornou tecnologicamente viável para a comercialização. Desde então, a embalagem tem mudado os hábitos de consumo das pessoas em todo o mundo, levando a praticidade para dentro de suas casas (ANTUNES, 2003).

Segundo Antunes (2003), o aparecimento do plástico como material para embalagem ocorreu após a segunda guerra mundial, pois eram mais leves, mais baratos e mais fáceis de produzir do que as embalagens de papel ou de metal.

O desenvolvimento das resinas de PVC teve início em 1835, quando Justus von Liebig descobriu o monômero cloreto de vinila (MVC), um gás à temperatura ambiente com ponto de ebulição igual $-13,8^{\circ} \mathrm{C}$. Sua descoberta foi realizada por meio da reação de dicloroetileno com hidróxido de potássio em solução alcoólica (NUNES, 2002). Porém, o primeiro relato da polimerização autêntica de um haleto de vinila foi feita por A.W. Hoffman em 1860, que notou a mudança do brometo de vinila para uma massa esbranquiçada sem mudança composicional (NUNES, 2002).

De acordo com Nunes (2002), a primeira produção comercial do PVC ocorreu nos anos 20 nos Estados Unidos. Os alemães conseguiram produzi-lo nos anos $30 \mathrm{e}$ os britânicos nos anos 40. No Brasil, a produção comercial teve início em 1954.

A produção comercial de PVC influenciou a comercialização de alimentos contribuindo para uma maior durabilidade dos alimentos, inclusive no âmbito do lar, tornando o produto acessível há um maior número de pessoas acarretando um ciclo virtuoso onde atualmente o filme de PVC é visto como protetor e vitrine de produtos.

\subsection{PROPRIEDADES DE BARREIRA}

Uma das principais funções da embalagem é de proteger o produto. Essa proteção se dá em dois aspectos. O primeiro aspecto é a proteção do produto contra danos físicos e mecânicos durante a movimentação, transporte e distribuição. O segundo aspecto é a proteção dos produtos, principalmente alimentos e bebidas, 
contra a ação de fatores ambientais como gases, luz, vapor d'água e odores (SARANTOPOULOS et al., 2002).

Melo (2007) corrobora as idéias de Sarantopoulos et al., 2002 na medida em que destaca a função de barreira de proteção contra o ambiente, evitando contaminações, manuseio inadequado, falta de higiene e perda das características próprias do produto, entregando ao consumidor um alimento com qualidade.

Assim, a embalagem proporciona ao consumidor um alimento com um nível de qualidade semelhante à dos produtos frescos ou recém-preparados, devido à sua capacidade de protegê-lo contra agentes deteriorantes, infectantes e sujidades (ESTEVES; et al., 2006).

As propriedades de barreira de uma embalagem não devem ser confundidas com sua resistência química, que está associada à sua capacidade de não ser afetada (solubilizada, alterada, amolecida) quando em contato com algum agente. Assim, a capacidade de uma embalagem de resistir à absorção ou à evaporação de gases e vapores, resistir à penetração de lípides e à passagem de luz é definida como barreira (SARANTOPOULOS et al., 2002).

De acordo com Melo (2007) e Sarantópoulos et al. (2002), a qualidade dos produtos alimentícios depende diretamente de fatores de natureza química, física e biológica que atuam sobre o alimento durante o período de tempo entre sua produção e seu consumo. Para que o alimento permaneça em condições adequadas muitas formas de conservação são utilizadas, seja isoladamente ou combinadas. Tratamento térmico, refrigeração, radiação, adição de aditivos e embalagens tem sido usados com agentes de conservação.

Dessa forma, é importante considerar as características e requerimentos do sistema produto/embalagem/ambiente como um todo, contemplando assim a interação do sistema (MELO, 2007). A legislação de Embalagens para Contato com Alimentos, Resolução de Diretoria Colegiada - RDC 105/99 e RDC 91/01 da ANVISA é chamada de "positiva", ou seja, somente as substâncias listadas em Listas Positivas de embalagens para alimentos são as substâncias permitidas para contato com alimentos, sempre respeitando os limites e/ ou restrições de uso. Se uma substância não estiver contemplada em Lista Positiva, significa que o seu uso está proibido até que a substância tenha sido avaliada, do ponto de vista de 
segurança de uso (MELO, 2007).

O contato das embalagens com o produto pode representar riscos para a saúde do consumidor devido à possibilidade de permeação de componentes indesejáveis e/ou a migração de constituintes da própria embalagem em concentrações acima dos limites permitidos.

Segundo Melo (2007), vários compostos provenientes do ambiente interno ou externo podem ser transportados através de polímeros, resultando em alterações contínuas e gradativas da qualidade do produto. Além disso, pode haver interações diretas do polímero com o alimento, como no caso de compostos de baixo peso molecular presentes na estrutura polimérica que migra para o produto, afetando sua segurança e qualidade.

No entanto, é preciso ter em mente que, quando o propósito da embalagem é preservar o produto estando em contato direto com ele, a composição do alimento também interfere na migração dos componentes presentes na embalagem. Assim, deve ser levada em consideração a composição do alimento para o qual a embalagem está sendo desenvolvida, o que tem sido um desafio para as indústrias de embalagens (MELO, 2007).

\subsection{EMBALAGENS PLÁSTICAS DE ALIMENTOS}

Nas últimas décadas o uso crescente de materiais poliméricos para embalagem de alimentos, principalmente plásticos, têm sido marcante, devido, especialmente, a fatores mercadológicos como transparência, leveza, resistência a quebras, versatilidade de formatos e tamanhos, além dos sistemas de fechamento. Além disso, os custos são altamente competitivos, tornando os plásticos extremamente atraentes para os produtores e usuários de embalagens.

De acordo com Antunes (2003) e Nunes (2002), os polímeros podem ser divididos em dois grandes grupos, os termofixos e os termoplásticos. A maioria das embalagens, destinadas ao acondicionamento de alimentos, são produzidas com resinas termoplásticas, que possuem a capacidade de amolecer e fluir ao serem submetidos a um aumento de temperatura e pressão. De acordo com Melo (2007), estas resinas podem ser transformadas por processos termomecânicos, sendo os mais representativos: extrusão, injeção, sopro e termoformação. Entre os 
termoplásticos mais usados para embalar alimentos encontram-se o polietileno, o polipropileno, o poliestireno, o policloreto de vinila e o poli (teraftalato de etileno).

Muitos materiais plásticos recebem aditivos para aumentar sua vida útil, eliminar ou fornecer características às suas propriedades e também de coadjuvantes de processo que contribuem de forma a melhorar o processamento do material (ANTUNES, 2003; NUNES, 2002). Segundo Melo (2007), estes compostos são incorporados no processo de fabricação da resina para uma homogeneização mais perfeita do material e para que suas propriedades sejam mais constantes. Por exemplo, o PVC necessita ser adicionado de aditivos devido a sua baixa estabilidade térmica e alta viscosidade à fusão, que lhe permite uma maior mobilidade e flexibilidade.

\subsection{POLICLORETO DE VINILA - PVC}

O policloreto de vinila (PVC) pode ser classificado em rígido e flexível. O tipo rígido tem boa resistência mecânica e estabilidade dimensional. Já o tipo flexível apresenta como características flexibilidade e extensibilidade, devido à presença de plastificantes em sua formulação.

A obtenção do PVC é a partir da polimerização do cloreto de vinila que é sintetizado a partir do dicloroetileno, que por sua vez é obtido a partir da reação entre o cloro e o etileno. O etileno é derivado da indústria petroquímica, porém o cloro é extraído do cloreto de sódio, $\mathrm{NaCl}$. Dessa forma, o PVC é um polímero derivado $43 \%$ do petróleo e $57 \%$ de fonte inorgânica, o sal $\mathrm{NaCl}$ (SARANTOPOULOS et al., 2002). É uma cadeia polihalogenada com átomos de cloro ligados covalentemente a átomos de carbono. Apresentam-se com muitas ligações dipolo-dipolo ao longo da cadeia ocasionando fortes interações e conseqüente rigidez do material polimérico. Aditivos, como os plastificantes, quebram estas interações dipolares permitindo uma maior mobilidade e flexibilidade do material (MELO, 2007).

Segundo Nunes (2002), a presença do átomo de cloro em sua estrutura molecular torna o PVC um polímero naturalmente resistente à propagação de chamas, contribuindo para aplicações nas quais o retardamento à chama é item desejado, tais como em fios e cabos elétricos, eletrodutos e forros/revestimentos 
residenciais. Além disso, o grande teor de cloro presente na estrutura molecular do PVC torna sua molécula polar, o que aumenta sua afinidade e permite sua mistura com uma gama de aditivos muito maiores que a de qualquer outro termoplástico, possibilitando a preparação de formulações com propriedades e características perfeitamente adequadas a cada aplicação.

O PVC é produzido quando as moléculas de cloreto de vinila se associam, formando cadeias de macromoléculas. Este processo é chamado de polimerização e pode ser realizado de várias maneiras. Os dois principais processos de obtenção do PVC são a polimerização em suspensão e a polimerização em emulsão. Ambos usam um processo semi-contínuo, em que os reatores são alimentados com o monômero cloreto de vinila (MVC), aditivos e catalisadores (NUNES, 2002).

Como o MVC tem propriedades tóxicas, é muito importante que ele não seja liberado para a atmosfera nem permaneça no produto. Por essa razão, várias etapas do processo e as características dos equipamentos são concebidas para evitar tais perdas. Isso permite que as resinas contenham menos de um grama (1g) de MVC por tonelada de PVC (NUNES, 2002).

O PVC é utilizado para fabricar embalagens para água mineral, óleos comestíveis, maioneses, sucos, perfis para janelas, tubulações de água e esgotos, mangueiras, brinquedos infantis, pisos de vinil, interiores de carros, entre outros.

De acordo com Antunes (2003), a produção mundial corrente de PVC excede 20 milhões de toneladas, sendo a Ásia a maior região produtora, seguida pelos Estados Unidos e pela Europa. A partir dos anos 70, essa resina passou a sofrer uma pressão crescente dos ambientalistas por fazer mal ao meio ambiente e a saúde humana, pois envolve em sua composição cloro e derivados organoclorados.

Muitos organoclorados, oriundos tanto de fontes agrícolas como industriais, apresentam, frequentemente, alta resistência à degradação química e biológica e alta solubilidade em lipídios. A combinação entre a baixa solubilidade em água e a alta capacidade de adsorção na matéria orgânica leva ao acúmulo desses compostos ao longo da cadeia alimentar, especialmente nos tecidos ricos em gorduras dos organismos vivos (FLORES; et al., 2004). As restrições ao uso de organoclorado originam-se da sua grande capacidade residual e possível ação carcinogênica estando, assim, a população exposta a eles seja pela água, ar ou 
alimentos (NUNES; TAJARA, 1998).

O PVC é a segunda resina plástica mais vendida, perdendo apenas para o polietileno. Suas aplicações são tão amplas como sua versatilidade em propriedades, sendo a indústria de construção civil seu mercado mais significativo. No segmento de embalagens, o PVC é usado em filmes plastificados esticáveis (stretch), muito usados como envoltórios de produtos in natura, carnes, frangos, frutas (para uso nos supermercados e caseiro) e para filmes termoencolhíveis para lacres, rótulos ou para envoltórios (overwrapping) de outras embalagens (multipacks ou display packaging) (SARANTOPOULOS et al., 2002).

As propriedades do PVC são fortemente afetadas pela quantidade e tipo de aditivos de sua formulação. Dessa forma, as resinas podem ser desenvolvidas com propriedades específicas para a aplicação, atendendo requisitos tão distintos como os de filmes flexíveis transparentes e os de tubulações (NUNES, 2002).

Portanto, o plastificante a ser utilizado deve considerar fatores como custo, cor, odor, sabor, biodegradabilidade, temperatura de estabilidade, resistência à migração, potencial toxicológico para ter sua aplicação aprovada (MELO, 2007).

\subsubsection{ADITIVOS}

Os aditivos são incorporados às resinas plásticas para modificar algumas características, melhorando o desempenho dos polímeros durante a fabricação e utilização. Os principais aditivos utilizados são:

$\checkmark$ antioxidantes, que retardam as reações oxidativas que comprometeriam as propriedades mecânicas do material;

$\checkmark$ deslizantes, que lubrificam o material, reduzindo o coeficiente de atrito;

$\checkmark$ aditivos antibloqueio, que reduzem a aderência entre superfícies de filmes, facilitando o manuseio;

$\checkmark$ antiestáticos, que reduzem o efeito eletrostático, evitando a aderência de filmes entre si ou com partículas do ambiente carregadas eletrostaticamente; e

$\checkmark$ plastificantes, que aumentam a flexibilidade do polímero. 
Muitos aditivos apresentam potencial de atividade cancerígena, segundo indicam estudos epidemiológicos (ESTEVES et al., 2006; MELO, 2007). Isto porque esses aditivos podem migrar para o alimento; há taxas que dependem da concentração do aditivo, tempo e temperatura, representando uma fonte de contaminação e podendo comprometer a segurança do consumidor (LAU; WONG, 2000). Um aditivo de embalagens que tem recebido bastante atenção por parte da mídia é o DEHA, um plastificante que pode migrar para certos alimentos, especialmente aqueles com alto teor de lipídios; entretanto, os níveis geralmente ingeridos são bem inferiores aos níveis avaliados em estudos com animais, que não apresentaram efeitos tóxicos (FOOD AND DRUG ADMINISTRATION - FDA, 2002).

Em virtude da importância dos plastificantes para a flexibilidade no filme de PVC e devido ao seu potencial de migração para alimentos gordurosos e sua toxicidade estes assuntos serão destacados no item a seguir.

\subsubsection{Plastificantes usados em PVC}

De acordo com Sarantópoulos et al. (2002), os plastificantes são líquidos orgânicos de baixa volatilidade que facilitam o movimento molecular das cadeias. São adicionados à formulação de um polímero para reduzir a dureza no produto acabado, alterando fortemente seu comportamento mecânico. Segundo a IUPAC (International Union of Pure and Applied Chemistry ou União Internacional de Química Pura e Aplicada) plastificante é definido como "substância incorporada ao plástico ou elastômeros com a finalidade de aumentar sua flexibilidade, processabilidade ou capacidade de alongamento" (MELO, 2007).

Dessa forma, os plastificantes, segundo Melo (2007), atuam enfraquecendo as forcas de atração entre as moléculas, facilitando o deslizamento entre elas, pela redução das ligações polímero-polímero e criação das interações polímeroplastificante.

Para que os plastificantes sejam aceitáveis existem algumas características desejáveis, tais como: baixa inflamabilidade, baixa toxicidade, ausência de sabor, odor e cor, baixa migração, alta resistência térmica aos raios ultravioletas, boas características de processamento e baixo custo. Assim, algumas características podem ser essenciais dependendo da aplicação do material; por exemplo, para a 
produção de embalagens para alimentos é essencial que o aditivo seja atóxico e não possua cor, sabor e odor (ANTUNES, 2003; MELO, 2007; NUNES, 2002).

Dentre os plastificantes mais utilizados na fabricação do PVC encontram-se o estearato de butila, citrato de acetil-tributila, sebacato de alquila e adipatos, que apresentam baixa toxicidade; já os ftalatos têm seu potencial carcinogênico e histogênico mais acentuados (LAU, WONG, 2000). Porém, o foco da pesquisa são o DEHP e o DEHA.

Sendo os plastificantes moléculas de baixo peso molecular e que na maioria das vezes não estão quimicamente ligados à cadeia polimérica, estes podem migrar facilmente para o produto acondicionado. Esta migração pode ocorrer quando a embalagem sofre abrasão, quando esta é colocada em solução ou quando o plastificante sofrer lenta evaporação, ou ainda pelo contato de um sistema plastificado com outro não plastificado, como por exemplo o alimento (MELO, 2007; PADULA, 1995).

Segundo Sarantopoulos et al. (2002) a razão mais comum pela qual um consumidor rejeita um produto alimentício é a alteração de seu odor e/ou sabor. Esta alteração pode estar relacionada com as transformações do próprio alimento como envelhecimento, oxidação de lipídeos e de componentes responsáveis pelo aroma característico, escurecimento não enzimático, escurecimento enzimático, reações de oxidação induzidas pela luz, aglomeração e desenvolvimento microbiológico. Estas alterações podem ainda estar relacionadas com a absorção de odores do ambiente, perda do odor característico por permeação, ou ainda pela interação embalagem/alimento (SARANTOPOULOS et al., 2002).

Segundo o mesmo autor, teoricamente, nenhuma embalagem é livre do potencial de transferir odor e/ou sabor estranho ao produto alimentício. Assim, várias são as substâncias que podem migrar da embalagem plástica para alimentos, como: monômeros, oligômeros, solventes de impressão e laminação, produtos de degradação térmica, entre outros. São compostos que possuem normalmente baixo peso molecular e, portanto, possuem mobilidade no material plástico e podem então interagir com o produto acondicionado causando contaminação toxicológica ou mesmo sensorial.

Para Melo (2007), em um sistema alimento-embalagem-ambiente, os 
processos de transferência de massa são descritos como interações alimentoembalagem, e estas interações são classificadas em três categorias:

$\checkmark$ Migração: é a transferência de moléculas originalmente presentes no material de embalagem para o alimento ou ambiente;

$\checkmark$ Sorção: consiste na absorção de componentes pelo material de embalagem;

$\checkmark$ Permeação: é a transferência de compostos do produto para 0 ambiente ou vice-versa, através do material de embalagem.

A migração e a sorção são processos de difusão, enquanto a permeação é função da difusividade e da solubilidade do composto na embalagem.

Segundo Padula (1995), Sarantópoulos et al. (2002) e Antunes (2003) vários componentes dos polímeros podem migrar para o alimento, principalmente monômeros residuais do processo da fabricação e aditivos incorporados ao material. As consequências das interações alimento-embalagem são diversas. O sabor dos alimentos pode sofrer alterações em decorrência da permeação de compostos do ambiente através da embalagem, reações químicas da embalagem com o alimento e por migração de compostos da embalagem para o alimento. A migração de compostos da embalagem pode comprometer a resistência química e mecânica do material da embalagem além de poder acarretar consequências toxicológicas. No caso da migração, a embalagem pode afetar a estabilidade do alimento, assim como o alimento pode afetar a estabilidade da embalagem, levando dessa forma a uma redução gradativa da qualidade do produto.

A migração de monômeros e aditivos de embalagens plásticas para os alimentos em contato depende das características físico-químicas do alimento, tais como $\mathrm{pH}$, presença de óleos, essências, porcentagem de lipídeos, teor alcoólico. Outros fatores também influenciam significativamente a migração, como a temperatura e tempo de contato da embalagem com o alimento, relação superfície de contato/volume de alimento, espessura da embalagem plástica além das várias técnicas utilizadas no acondicionamento de alimentos (vácuo parcial, esterilização na própria embalagem) (MELO, 2007; PADULA, 1995)

Dessa forma, nas três ultimas décadas a comunidade científica internacional tem voltado sua atenção para os aspectos toxicológicos decorrentes da utilização de 
materiais de síntese química nas embalagens para alimentos, surgindo a necessidade de estabelecer uma legislação especifica para seu controle (MELO, 2007).

No Brasil, testes para avaliar a compatibilidade de aditivos com materiais de embalagem, bem como uma lista de substâncias que podem ser empregadas na elaboração de embalagens para alimentos e seus limites de migração, estão descritos na Resolução RDC n¹7/2008. Na referida resolução consta a Lista Positiva $^{1}$ de Aditivos para embalagens plásticas para contato com alimentos da agência governamental que trata de assuntos relativos a alimentos - ANVISA vinculada ao Ministério da Saúde. Nela esta descrito o limite de migração global para embalagens plásticas em alimentos (50 mg. $\mathrm{kg}^{-1}$ ou $8 \mathrm{mg} \cdot \mathrm{dm}^{-2}$ ), diferindo da União Européia que tem valores superiores $\left(60 \mathrm{mg} \cdot \mathrm{kg}^{-1}\right.$ ou $10 \mathrm{mg} \cdot \mathrm{dm}^{-2}$ ). (ANVISA, 2008; COMMISSION DIRECTIVE, 2002).

Tabelas que regem as análises de migração de componentes de materiais poliméricos estão descritas na Resolução 105/99 da ANVISA e na Diretiva 2002/72 da Comunidade Européia (ANVISA, 1999; COMMISSION DIRECTIVE, 2002).

Ressaltando, os produtos de PVC podem ser classificados como pertencentes a dois grandes grupos: rígidos e flexíveis. A resina de PVC é naturalmente rígida; entretanto, durante a produção dos compostos de PVC, uma classe especial de aditivos pode ser incorporada à resina de PVC de modo a gerar compostos flexíveis: os plastificantes.

A IUPAC define os plastificantes como "substâncias incorporadas a plásticos ou elastômeros com a finalidade de aumentar sua flexibilidade, processabilidade ou capacidade de alongamento. Um plastificante pode reduzir a viscosidade do fundido, abaixar sua temperatura de transição de segunda ordem (temperatura de transição vítrea ou $\mathrm{T}_{\mathrm{g}}$ ) ou diminuir seu módulo de elasticidade." Dessa forma, pode-se definir plastificantes como toda e qualquer substância que, incorporada ao PVC, reduz sua dureza e aumenta sua flexibilidade (NUNES, 2002).

Os plastificantes comerciais são, geralmente, líquidos inodoros, incolores, insolúveis em água e de baixa volatilidade. São, em sua maioria, ésteres ou poliésteres, incluindo outros com base em ácidos adípicos, fosfóricos, sebáceos,

\footnotetext{
${ }^{1}$. Uma lista positiva significa que somente o que está publicado nessa lista ou tabela é permitido.
} 
trimelíticos ou azeláticos (NUNES, 2002; SARANTOPOULOS et al., 2002).

Plastificantes, como os ftalatos e adipatos, são comumente utilizados na manufatura de PVC seja para uso em embalagens de alimentos, em produtos médicos, artigos infantis entre outras utilidades. Em consequência dos casos de migração destes componentes, estudos de toxicidade têm sido realizados (AZEREDO, 2004).

Dentre os plastificantes, o DEHP é o composto mais conhecido e estudado do ponto de vista toxicológico (SARANTOPOULOS et al., 2002). Sua toxicidade aguda é muito baixa, tendo sido considerado seguro por longo tempo. No entanto, na década de 1980, com a realização de testes crônicos de toxicidade foi notado que sua administração oral pode causar tumores no fígado, além de toxicidade no sistema reprodutivo com atrofia testicular, afetar órgãos como cérebro, rins e pulmão de ratos e camundongos (MELO, 2007; SOUZA; CORIO; TEMPERINI, 2003).

Devido aos efeitos toxicológicos do DEHP, estudos de plastificantes alternativos têm sido realizados. A semelhança da estrutura química do DEHP e DEHA e de seus metabólitos gera a suspeita de toxicidade do DEHA. Estes plastificantes apresentam um metabólito comum, o 2-etil-hexanol (2-EH) e, de acordo com Melo (2007), há a hipótese de que este metabólito pode estar relacionado a alguns aspectos quanto à toxicidade reprodutiva. Segundo Melo (2007), os pesquisadores obtiveram um resultado de potencialização do efeito tóxico alcançado em seus estudos quando combinaram DEHP e DEHA, porém nenhum efeito tóxico foi detectado quando o DEHA foi ministrado separadamente.

Cabe destacar que alguns estudos sobre a migração de plastificantes, como o DEHP e o DEHA, para alimentos gordurosos apontam que estes podem prejudicar a saúde humana. Estes plastificantes são classificados como grupo três pela ANVISA, que são considerados como "risco cancerígeno para seres humanos não classificável", isto é, risco ainda não evidenciado para seres humanos, segundo a Organização Mundial de Saúde (OMS).

A migração, que é a transferência de moléculas originalmente presentes no material de embalagem para alimentos ou ambiente, e a sorção, que consiste na absorção de componentes pelo material de embalagem, são processos de difusão, enquanto a permeação é função da difusividade e da solubilidade do composto na 
embalagem. A permeação é afetada pela polaridade e pelo peso molecular do permeante, que afetarão diretamente sua solubilidade e difusividade, respectivamente. Além disso, quanto maior a concentração do permeante, maior sua taxa de transporte através da estrutura do polímero (PADULA, 1995; SARANTOPOULOS et al., 2002).

As consequências das interações alimento-embalagem são diversas. Por exemplo, o sabor do alimento pode sofrer alterações em decorrência de permeação de compostos do ambiente através da embalagem, reações químicas da embalagem com o alimento e migração de compostos da embalagem pode ter, ainda, consequências toxicológicas (AZEREDO, 2004). Vários componentes dos polímeros podem migrar para o alimento, principalmente monômeros residuais do processo de fabricação e aditivos incorporados ao material.

Os aditivos usados para deixar os filmes de PVC maleáveis não se ligam quimicamente ao produto e podem migrar para os alimentos com os quais ficam em contato. A migração, que acontece por difusão espontânea, é mais intensa em alimentos gordurosos devido à semelhança entre sua composição química e aquela encontrada nos aditivos usados pela indústria. O DEHP e o DEHA são os compostos orgânicos usados para conferir flexibilidade aos filmes plásticos (ABRANTES, 2007; ESTEVES et al., 2006).

De acordo com Esteves et al. (2006), a migração dos ftalatos para alimentos gordurosos tem sido conhecida como uma contaminação em potencial nos alimentos. Equipamentos utilizados em processos, tais como tubos de PVC, revestimentos de superfície e juntas usadas em indústrias de alimentos que entram em contato direto com os alimentos podem ser focos em potencial de contaminação destes. Outras formas de contaminação dos alimentos pelo DEHP que podem ser destacados são o ar atmosférico que se deposita na lavoura e águas que possuam ftalato. Apesar de o homem estar sujeito a várias formas de exposição ao DEHP, tem sido de muito interesse por alguns autores estimar a migração do DEHP no alimento. Entretanto, o número de publicações ainda é limitado devido a dificuldades analíticas em determinar baixas concentrações.

Segundo Esteves et al. (2006) o DEHP é um composto tóxico, uma vez que estudos recentes têm demonstrado que este aditivo em ratos e camundongos pode causar atrofia testiculoar, pois possui efeito antiandrogênico, antagonizando os 
efeitos da testosterona. Estudos experimentais têm demonstrado que o DEHP causa redução de peso, embriotoxicidade, atrofia testicular, hepatotoxicidade e anormalidade no sistema nervoso central em ratos e camundongos. A toxicidade aguda em humanos é baixa e a crônica resulta efeitos no fígado (GIUST et al., 1994)

O DEHP pode ser encontrado no meio ambiente através da sua liberação pelas fábricas que o produz ou o utiliza, podendo ser liberado também mediante a queima de plástico. O DEHP pode se espalhar no meio ambiente próximo a áreas industriais, campos e locais de depósito de lixo, bem como pode ser encontrado em águas subterrâneas próximas a estes tipos de locais citados anteriormente. Quando o DEHP é liberado no solo o ataca fortemente e consegue se mover para longe do local no qual foi liberado (U. S. DEPARTAMENT OF HEALTH AND HUMAN SERVICES, 1993).

\subsection{COMPETÊNCIA SANITÁRIA}

A contaminação de alimentos por migração de aditivos é assunto que compete à legislação sanitária. Os materiais de embalagem destinados ao acondicionamento de alimentos devem ser avaliados pela Autoridade Sanitária Nacional Competente quanto à segurança de seu uso. Se aprovados, publica-se a inclusão na Lista Positiva correspondente. Também é comum na legislação a definição de um limite de migração total, que apesar de não envolver diretamente aspectos toxicológicos, é um controle do potencial de contaminação indireta do produto alimentício e do potencial de interação material de embalagem do produto.

A ANVISA esclarece que o cloreto de vinila, monômero do PVC, libera quando aquecido, ácido clorídrico e compostos voláteis tóxicos. Para este, a legislação brasileira estabelece o limite de $1 \mathrm{mg} / \mathrm{kg}$ na estrutura do polímero final.

Pesquisa realizada pelo Instituto Nacional de Controle de Qualidade em Saúde (INCQS) da Fundação Oswaldo Cruz (FIOCRUZ) alerta para uma lacuna na legislação brasileira que pode dar brecha para o uso excessivo de substâncias potencialmente cancerígenas nos filmes plásticos destinados à embalagem de alimentos. A conclusão é fruto de três anos de estudo sobre os dois tipos de aditivos mais comumente usados para conferir flexibilidade aos filmes de policloreto de vinila (PVC), que podem ser prejudiciais à saúde quando em contato com alimentos 
gordurosos como queijo mussarela, frango e carne bovina (ESTEVES et al.,2006).

A legislação brasileira prevê limites para a presença do DEHP, que se mostrou ligado ao desenvolvimento de câncer no fígado e a problemas de fertilidade em animais de laboratório. Após a atualização da lista positiva, que será comentado no item a seguir, o Limite de Migração Especifica (LME) para o aditivo DEHA foi acrescentado a ela, completando, assim, as solicitações dos Estados Membros do MERCOSUL (ANVISA, 2008)

\subsubsection{LEGISLAÇÕES PARA EMBALAGENS DE ALIMENTOS}

As legislações que tratam da adequação de materiais de embalagem para contato com alimentos visam assegurar a saúde do consumidor através do controle sobre a contaminação química de produtos alimentícios devido à migração de componentes da embalagem.

A legislação brasileira de embalagem para contato direto com alimentos foi atualizada e harmonizada com a formação do Mercado Comum do Sul MERCOSUL. Assim, como as demais legislações no mundo, a legislação brasileira apresenta as Listas Positivas de Monômeros e Aditivos e requer ensaios de migração total e, de migração especifica e de conformidade com os limites de composição, quando necessário. A legislação brasileira continua a ser atualizada, sempre que possível, pela ANVISA, que é o órgão responsável no Brasil pelas legislações sanitárias sobre embalagens para alimentos (ANTUNES, 2003).

Como comentado anteriormente, ANVISA atualizou recentemente na Resolução RDC n¹7, de 17 de março de 2008, a lista positiva de aditivos para materiais plásticos destinados à elaboração de embalagens e equipamentos em contato com alimentos, fundamentando-se na avaliação da segurança de uso dos aditivos, devido aos danos que estes podem causar ao alimento e à saúde humana (ANVISA, 2008).

Na RDC no 91, de 11 de maio de 2001, que aprova o Regulamento Técnico de Critérios Gerais e Classificação de Materiais para Embalagem e Equipamentos em Contato com Alimentos, adotam-se quatro princípios que regem os componentes utilizados nos materiais destinados a entrar em contato com alimentos. Os princípios afirmam que esses componentes devem: 
$\checkmark$ Estar incluídos nas listas positivas que são relações taxativas de substâncias que provaram ser fisiologicamente inócuas em ensaios com animais e cujo uso está autorizado para a fabricação de materiais em contato com alimentos. Estas listas poderão ser modificadas de acordo com os critérios descritos no Anexo I do Regulamento citado.

$\checkmark$ Em alguns casos, para alimentos específicos, ser estabelecidas restrições de uso.

$\checkmark$ Seguir critérios de pureza compatíveis com sua utilização.

$\checkmark$ Cumprir com o limite de migração total estabelecido e com os limites de migração específica estabelecidos para certos componentes.

Também está registrado na RDC n 91/2001 que para a inclusão e exclusão de componentes e para a atualização das restrições, devem ser utilizadas, como referência, de acordo com a ordem abaixo:

$\checkmark$ As Listas Positivas das Diretivas da União Européia e os Documentos Sinópticos da Commission of the European Communities - Directorate General III - Industry;

$\checkmark$ As Listas Positivas do Food and Drug Administration - FDA (Code of Federal Regulations - Título 21 capítulo 176);

$\checkmark$ Outras legislações européias mencionadas na legislação nacional, específicas para cada tipo de material, atualizadas;

$\checkmark$ Excepcionalmente podem ser consideradas as listas positivas de outras legislações internacionalmente reconhecidas.

Essas referências também são seguidas para o estabelecimento de limites de migração total e específica, limites de composição e ensaios de migração total e específica determinados na legislação vigente de embalagens e equipamentos para contato com alimentos.

Assim sendo, este trabalho foi desenvolvido a fim de investigar a adequação da legislação sanitária pertinente à utilização de aditivos plastificantes, que possuem restrição de uso em alimentos gordurosos, em filme plástico de PVC utilizados pelas redes de hipermercados e supermercados do Plano Piloto - Brasília, Distrito Federal, para embalar alimentos gordurosos como queijo mussarela, presunto, carne 
in natura e embutidos. 


\section{METODOLOGIA}

A presente pesquisa tem um caráter transversal exploratório e se propôs a investigar as embalagens de filme de PVC que são destinadas ao uso de alimentos gordurosos como queijo mussarela, presunto, carne in natura e embutidos, nas redes de hipermercados e supermercados do Plano Piloto, Brasília, Distrito Federal.

Cabe destacar que toda a coleta de dados foi realizada pelo coordenador da pesquisa.

\subsection{SELEÇÃO DOS LOCAIS DE PESQUISA}

Foi selecionado, por sorteio aleatório, 01 (um) hipermercado de cada rede de hipermercados existente no Planto Piloto, Brasília-DF e 01 (um) supermercado de cada rede de supermercados que funciona no Planto Piloto, Brasília-DF.

\subsection{IDENTIFICAÇÃO DOS ALIMENTOS QUE USAM FILME PVC}

Nos estabelecimentos selecionados observou-se o uso do filme de PVC, em bobinas, em alimentos gordurosos, especificamente: queijo mussarela, presunto, carne in natura e embutidos, conforme a figura 1 abaixo, pois são os alimentos cuja migração tem sido mais freqüentemente investigada, segundo Esteves et al. (2006) e Melo (2007).

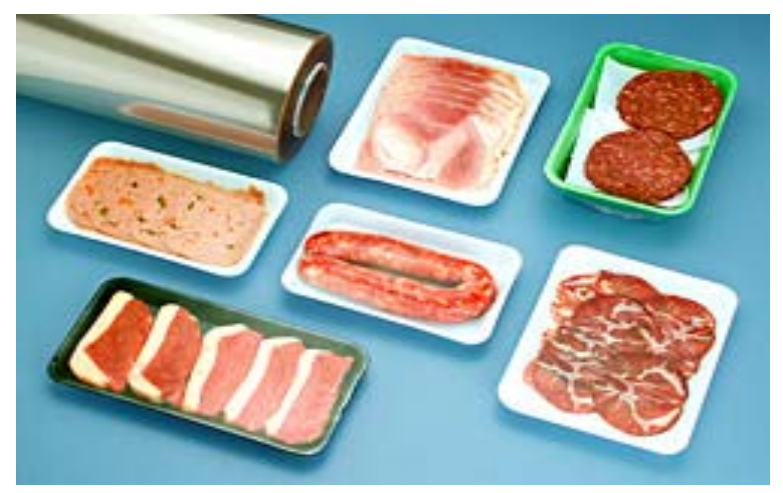

Figura 1: Alimentos embalados com filme de PVC

Para a observação, foi necessária uma visita em cada estabelecimento selecionado e, nas seções de cada produto indicado, observou-se o uso do filme flexível, em bobinas. 


\subsection{IDENTIFICAÇÃO DOS TIPOS DE FILMES DE PVC}

Em cada hipermercado e supermercado correspondente de uma rede, após a verificação dos produtos mencionados (queijo mussarela, presunto, carne in natura e embutidos) que faziam uso do filme de PVC em bobinas, conforme a figura 2, para uso comercial pediu-se ao funcionário responsável pelo setor, sempre fazendo uma prévia identificação, que mostrasse a embalagem em que as bobinas de filme PVC estavam acondicionadas.

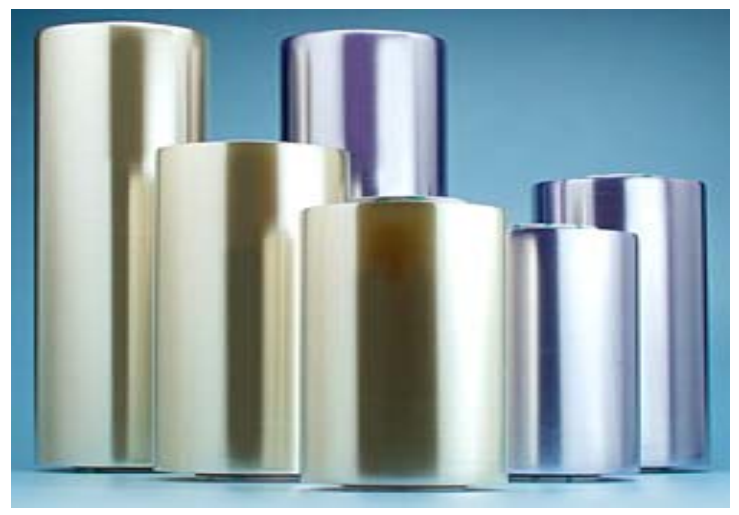

Figura 2: Filme de PVC em bobinas.

Verificou-se nas embalagens a presença de rótulos com informações da composição química do produto, o nome da marca, se continha alguma forma de contato, como Serviço de Atendimento ao Consumidor (SAC) ou endereço eletrônico, para que pudéssemos averiguar as informações.

Nas embalagens em que não houvesse informações foi feita uma investigação nos sítios eletrônicos de busca e/ou de órgãos governamentais, como no caso das informações do sítio da Receita Federal, para identificar a empresa pelo seu CNPJ.

\subsection{LEITURA E AVERIGUAÇÃO DOS FILMES DE PVC}

Depois de realizadas todas as visitas aos estabelecimentos e coletados os dados, foi necessária uma investigação, por telefone, para identificar a marca do filme de PVC usada em cada rede, pois foi fornecido, pelo responsável do setor de cada estabelecimento, o nome do funcionário da empresa representante da marca do filme de PVC, de cada rede de hipermercado e supermercado, e o número de 
telefone para contato.

Após a identificação das marcas, foi feita uma pesquisa na internet para identificar os sítios eletrônicos de cada marca de filme de PVC. Com os sítios eletrônicos identificados procurou-se averiguar se esses disponibilizavam as informações sobre sua composição química ou restrições de uso.

Foram enviadas mensagens eletrônicas, para cada marca de filme de PVC, solicitando que fornecessem a composição química dos filmes de PVC, dando ênfase à concentração dos plastificantes DEHP e DEHA.

A quantidade de mensagens eletrônicas enviadas para as marcas identificadas nos estabelecimentos foram as mesmas. No início da investigação, foram enviadas mensagens uma vez por semana, depois o número de mensagens aumenta, tornando-se diárias. Dessa forma, foram enviadas cerca de vinte mensagens neste período para cada marca de filme de PVC. Essa intensidade de envios de mensagens se deu devido à demora do retorno das mesmas. Nas mensagens foi feita a devida identificação com todos os dados da pesquisadora e o motivo da pesquisa. 


\section{RESULTADOS E DISCUSSÃO}

Através da seleção dos locais de pesquisa, verificou-se que no Plano Piloto, Brasília-DF, existem três redes de hipermercados ( $A, B$ e $C$ ), e sete redes de supermercados, sendo que dois desses supermercados ( $a$ e b) fazem parte de dois grupos de duas redes de hipermercados (A e B). De acordo com Santos e Gimenez (1998), supermercado é o local onde as pessoas compram gêneros alimentícios e artigos de higiene, limpeza e beleza, frios, carnes, pães, hortifrutis e congelados. E hipermercado é um tipo de supermercado com grande variedade de itens, contendo tudo que um supermercado tradicional tem, com inclusão de eletrônicos, roupas.

O Quadro 1 mostra a quantidade de hipermercados e supermercados, da mesma rede, existentes nesta região e o total de hipermercados e supermercados pesquisados.

\begin{tabular}{|c|c|c|c|}
\hline Hipermercados & $\begin{array}{c}\text { Quantidades no } \\
\text { Plano Piloto }\end{array}$ & Supermercados & $\begin{array}{c}\text { Quantidades no } \\
\text { Plano Piloto }\end{array}$ \\
\hline $\mathrm{A}$ & 2 & $\mathrm{Aa}$ & 9 \\
\hline $\mathrm{B}$ & 2 & $\mathrm{Bb}$ & 6 \\
\hline $\mathrm{C}$ & 1 & $\mathrm{~d}$ & 9 \\
\hline \multirow{2}{*}{} & & $\mathrm{e}$ & 1 \\
\cline { 3 - 4 } & & $\mathrm{f}$ & 7 \\
\cline { 3 - 4 } & & $\mathrm{g}$ & 6 \\
\hline TOTAL & $\mathbf{5}$ & $\mathrm{h}$ & 1 \\
\hline
\end{tabular}

Quadro 1: Hipermercados e supermercados e suas quantidades na região do Plano Piloto.

Como a rede de hipermercado "A" e a rede de supermercado "Aa" fazem parte da mesma rede a marca de filme de PVC fornecida para ambas é a mesma. Ao visitar uma das lojas o funcionário responsável pelas embalagens do setor disponibilizou, sem restrições, o nome e o contato da marca de filme de PVC que o 
seu estabelecimento utiliza para acondicionar os alimentos identificados. Porém, o funcionário do setor não permitiu a visualização da embalagem em que as bobinas de filme de PVC eram acondicionadas. Para essa rede identificou-se somente uma marca de filme de PVC.

O mesmo resultado se observa com a rede de hipermercado " $\mathrm{B}$ " e a rede de supermercado "Bb", que fazem parte de uma mesma rede de hipermercado e supermercado. Contudo, ao visitar o estabelecimento o gerente da loja se prontificou a mostrar a embalagem da marca do filme de PVC. Na embalagem continha somente o nome da marca do filme e o número do CNPJ. Não continha mais nenhuma informação, nem mesmo o número de SAC. Com número do CNPJ foi possível identificar o nome da marca do filme de PVC

No hipermercado "C" as informações foram fornecidas pela central de atendimentos da rede que disponibilizou o nome da marca do filme de PVC. Em nenhum momento foi possível visualizar a embalagem do filme. Este estabelecimento, também, recebe somente uma marca de filme de PVC.

$\mathrm{Na}$ rede de supermercados "d" o responsável pelo setor informou à pesquisadora, após sua identificação e o assunto da pesquisa, que a sua empresa buscava adquirir produtos que estivessem dentro das leis. Informou o nome da empresa, e o número de contato, que representa a marca que é fornecida a bobina de filme de PVC. Esta empresa representa uma única marca de filme de PVC.

No supermercado "e" o funcionário mostrou a embalagem que acondicionava a bobina de filme de PVC. A embalagem não continha nenhuma informação sobre sua composição química e não havia o número do SAC; havia somente o nome da empresa que Ihes fornecia. O responsável pelo setor informou o nome e o número de telefone de contato do vendedor da empresa. Esta empresa trabalha com duas marcas de filme de PVC.

Na rede de supermercados "f" a secretária do escritório central disponibilizou o nome e o contato telefônico da empresa que lhes fornecia o filme de PVC, pois o funcionário responsável pelo setor não soube respondê-las. A empresa que fornece as bobinas de filme de PVC trabalha com quatro marcas diferentes e seu representante informou os nomes e os números de telefone de contatos de cada marca. 
Os supermercados "g" e "h" utilizam a mesma marca de filme de PVC comercializada pela rede de supermercados "d".

Com os nomes e os contatos das empresas que representam as marcas de filme de PVC, foram realizados os telefonemas a fim de identificar os nomes das respectivas marcas fornecidas para os estabelecimentos.

O vendedor da empresa representante que fornece para os supermercados "d", "g" e "h", se mostrou informado sobre a legislação sanitária de aditivos para embalagens plásticas. Ele ainda relatou que não existe uma fiscalização com a finalidade de averiguar a adequação dos filmes de PVC que embalam alimentos gordurosos com a legislação sanitária correspondente, pois já vivenciou situações em que seus concorrentes informaram que usam qualquer filme de PVC, não se importando com a fiscalização sanitária, pois a Vigilância Sanitária não inclui as embalagens para alimentos na verificação de Boas Práticas de Fabricação (BPF). O supervisor da área se prontificou em fornecer as informações sobre a composição química do filme de PVC e que enviaria pelo correio eletrônico da pesquisadora, porém não houve respostas até a presente data.

O proprietário da empresa que fornece o filme de PVC para a rede de supermercado "f" informou que trabalha com diversas marcas, porém fornece quatro marcas diferentes para essa rede. Ele comentou que a entrega dependia do melhor preço. No supermercado "e" o representante da marca de filme de PVC informou os nomes de duas marcas que, também, são utilizadas na rede de supermercado "f".

Até a conclusão da pesquisa não houve respostas das mensagens eletrônicas por parte de todas as marcas de filme de PVC. A Lei no 8.078 que dispõe sobre a proteção do consumidor, no Capítulo III, Art. 6º parágrafo III, assegura que a informação adequada e clara sobre os diferentes produtos e serviços, com especificação correta de quantidade, características, composição, qualidade e preço, bem como sobre os riscos que apresentem, são direito básicos do consumidor. Dessa forma, o descaso com a disponibilização de informações, sobre o uso do produto, das empresas fabricantes e representantes de marcas de filme de PVC, em relação ao seu consumidor, são evidentes no resultado da pesquisa (BRASIL, 1990).

A ausência de respostas, com as informações da concentração de DEHP e de DEHA, das empresas fabricantes de filme de PVC fere o Art. $8^{\circ}$ da Lei $n^{\circ} 8.078$, que 
obriga os fornecedores, em qualquer hipótese, a dar as informações necessárias e adequadas a respeito dos produtos e serviços colocados no mercado de consumo, de forma a orientar a correta forma de uso para não acarretar riscos à saúde ou segurança dos consumidores. No parágrafo único é relatado que, em se tratando de produtos industriais, ao fabricante cabe prestar as informações a que se refere o Art. $8^{\circ}$ da Lei $n^{\circ} 8.078$, por meio de impressos apropriados que devam acompanhar 0 produto (BRASIL, 1990). Pensando dessa maneira, seria correto se as empresas informassem, nas embalagens do filmes de PVC, sobre o uso correto do produto. Por exemplo, não usar este produto para embalar alimentos gordurosos; Ou: Este produto não deve ser utilizado para embalar alimentos com alto teor de gordura.

Devido à toxicidade e ao potencial de migração dos plastificantes DEHP e DEHA presentes nos filmes de PVC destinados a embalar alimentos gordurosos, as empresas fabricantes deste tipo de embalagem devem estar dentro das normas estabelecidas na Resolução no 17/2008, pois esses aditivos fazem parte da lista positiva de aditivos para materiais plásticos destinados à elaboração de embalagens e equipamentos em contato com alimentos, e possuem restrições de uso e limites máximos de migração específica (ANVISA, 2008).

De acordo com RDC $n^{\circ} 17 / 2008$ no art. $2^{\circ}$ o descumprimento desta Resolução constitui infração sanitária, sujeitando os infratores às penalidade da Lei $n^{\circ}$ 6.437, de 20 de agosto de 1977 (ANVISA, 2008), que configura infrações à legislação sanitária federal, estabelece as sanções respectivas, e dá outras providências (BRASIL, 1977).

Após a publicação da pesquisa realizada por Esteves et al., 2006, coordenada pela doutora em Química Shirley Abrantes, da FIOCRUZ, que sugere o uso restrito de filmes plásticos de PVC, devido à migração dos aditivos plastificantes DEHP e DEHA, cuja toxicidade já foi comentada, os representantes da indústria de PVC negam que o filme plástico de PVC represente uma ameaça à saúde (ABIFICC, 2009).

Em sua pesquisa Esteves et al. 2006, utilizou para a determinação da migração dos plastificantes DEHA e DEHP, filmes de PVC vendidos nos supermercados e armazéns do Rio de Janeiro. As 22 amostras recolhidas foram analisadas em laboratório e observou-se que as médias da migração em $\mathrm{mg} / \mathrm{kg}$ do DEHP e do DEHA para o solvente simulante foram muito superior ao LME 
determinado pela União Européia cujos, valores são: 3mg/kg de DEHP e 18mg/kg de DEHA.

Segundo os resultados da pesquisa de Esteves et al. (2006), a média da migração encontrada para o DEHP foi de $156,34 \mathrm{mg} / \mathrm{kg}$ e a média da migração encontrada para o DEHA foi de $147,41 \mathrm{mg} / \mathrm{kg}$ alimento, porém a média de migração encontrada foi de $156,34 \mathrm{mg} / \mathrm{kg}$ no solvente.

Dessa forma, mediante os resultados encontrados pela pesquisadora da FIOCRUZ., os consumidores poderão estar expostos a estes plastificantes cuja a toxicidade é conhecida e revisada por vários autores (ESTEVES et al., 2006).

De acordo com a Associação Brasileira de Instituições Filantrópicas de Combate ao Câncer (ABIFICC), em uma reportagem em seu sítio eletrônico de 25 de novembro de 2005, para Miguel Bahiense, diretor do Instituto do PVC, órgão representativo das indústrias que compõem a cadeia produtiva deste material, não há dados científicos que comprovem o potencial cancerígeno do DEHP e do DEHA (ABIFICC, 2009).

Segundo Bahiense o estudo da Fiocruz não leva em consideração a toxicidade desta substância. Além disso, as pesquisas existentes apontam que o DEHP em excesso pode causar câncer no fígado de ratos e que os mecanismos de ação, desta substância, nos organismos de ratos são diferentes nos seres humanos (ABIFICC, 2009).

Contudo, como é sabido, o DEHP é um composto tóxico e que este aditivo em ratos e camundongos pode causar atrofia testicular, pois possui efeito antiandrogênico, antagonizando os efeitos da testosterona. E pode causar ainda redução de peso, embriotoxicidade, hepatotoxicidade e anormalidades no sistema nervoso central em ratos e camundongos, e que a toxicidade aguda em humanos é baixa e a crônica resulta efeitos no fígado (GIUST et al., 1994).

Além disso, o uso de mamíferos para testes in vivo é devido à similaridade com a fisiologia humana. E é natural que semelhanças entre o funcionamento do organismo dos mamíferos os façam candidatos para as pesquisas aplicadas à saúde humana. Os roedores (ratos, camundongos, cobaias e hamsters) têm sido priorizados devido ao seu pequeno tamanho e também pelo fato de se reproduzirem rapidamente. Estes animais apresentam, como principal vantagem, o fornecimento 
de informações sobre o organismo como um todo, fato que não é conseguido com outros métodos, o que ainda possibilita o seu emprego em pesquisas científicas (CHORILLI; MICHELIN; SALGADO, 2007).

Com isso, não tem fundamento os argumentos contrários, aos resultados da pesquisa realizada pela pesquisadora da FIOCRUZ., do diretor do Instituto do PVC, nem tão pouco da veracidade quanto ao uso da experimentação animal nas pesquisa científicas.

Neste sentido, fica claro que deveriam existir fiscalizações por parte das autoridades da Vigilância Sanitária para garantir o cumprimento das exigências sanitárias quanto ao correto uso destes plastificantes na fabricação dos filmes plásticos de PVC, assim como a fiscalização dos outros diversos tipos de embalagens para alimentos, dada a sua relevância para a Saúde Pública Nacional. 


\section{CONCLUSÃO}

O objetivo proposto para a presente pesquisa foi à identificação das embalagens de filme de PVC, em bobina, utilizadas para acondicionar alimentos gordurosos como queijo mussarela, presunto, carne in natura e embutidos, comercializadas nos hipermercados e supermercados do Plano Piloto, Brasília, Distrito Federal.

Os objetivos do trabalho foram cumpridos, tendo em vista que a identificação das marcas de filme de PVC, em bobina, e o tipo de embalagem em que são comercializadas não fornecem informações adequadas, não estando, dessa forma, em conformidade com a Resolução RDC no17/2008 da ANVISA.

Neste sentido, o ponto mais importante da pesquisa que foi a verificação nas embalagens de filme de PVC se havia informações sobre a presença dos aditivos DEHP e DEHA e/ou a restrição do seu uso em alimentos gordurosos foi desfavorecida, pois nas embalagens averiguadas não haviam informações e não obteve-se respostas por parte dos fabricantes de filme de PVC sobre a composição química e a concentração destes aditivos.

Dessa forma, notou-se a fragilidade da Lei de proteção ao consumidor e a falta de uma resolução que determine um aviso nas caixas da embalagem dos filmes de PVC sobre que tipos de alimentos não devem ser embalados nestes filmes flexíveis, para que a população seja alertada com relação ao risco toxicológica que esta exposta.

Outro ponto relevante para a pesquisa foi à despreocupação das redes de hipermercados e supermercados em fornecer alimentos gordurosos embalados em filmes de PVC que não estão de acordo com as normas da ANVISA. Isso ocorrer devido a falta de divulgação e informação a respeito do risco da migração e, conseqüentemente, a contaminação dos alimentos. 


\section{Referência Bibliográfica}

ABRANTES, S.. (org.). Validação em laboratório de métodos analíticos para a determinação do teor de adipatos e ftalatos de di-(2-etil-hexila) utilizados como plastificantes em filmes flexíveis de PVC. Química Nova, Vol. 30, No. 1, 219-223, 2007.

AGUIAR, R. Estudo traz alerta para a indústria de plásticos para embalar alimentos. Disponível em: http://www.ipetrans.hpg.com.br/PVC-FIOCRUZ.htm. Acessado em 09 de dezembro de 2008.

ANVISA (Agência Nacional de Vigilância Sanitária). Resolução n 105/99 - Aprova os Regulamentos Técnicos: Disposições Gerais para Embalagens e Equipamentos Plásticos em contato com Alimentos e seus Anexos. Brasil. Diário Oficial, 20 de maio de 1999.

ANVISA (Agência Nacional de Vigilância Sanitária). Resolução nº 91/01 - Aprova o Regulamento Técnico - Critérios Gerais e Classificação de Materiais para Embalagens e Equipamentos em Contato com Alimentos constante do Anexo desta Resolução. Brasil. Diário Oficial, 11 de maio de 2001.

ANVISA (Agência nacional de vigilância Sanitária). Resolução no 17/2008 - Aprova o Regulamento Técnico - sobre Lista Positiva de Aditivos para Materiais Plásticos destinados a Elaboração de Embalagens e Equipamentos em Contato com Alimentos. Brasil. Diário Oficial, 17 de março de 2008.

ANTUNES, Adelaide. (coord.). Prospectiva tecnológica da cadeia produtiva de embalagens plásticas para alimentos. Executor: Sistema de informações sobre a indústria química da escola de química, Universidade Federal do Rio de Janeiro (SIQUIM/EQ/UFRJ). Rio de Janeiro, 2003.

ABIFICC. Associação Brasileira de Instituições Filantrópicas de Combate ao Câncer. Disponível em: http://www.abifcc.org.br/dnews05.html, Acesso em: 12/03/2009.

AZEREDO, H. M. C. Embalagens e Estabilidade de Alimentos. In: AZEREDO, H.M.C. Fundamentos de Estabilidade de Alimentos. Fortaleza, Embrapa Agroindústria Tropical, 2004. 195p.

BRASIL. Presidência da República. Lei n. 6.437, de 20 de agosto de 1977. Configura as infrações à legislação sanitária federal, estabelece as sanções respectivas, e dá outras providências. 1977.

BRASIL. Presidência da República. Lei n. 8.078, de 11 de setembro de 1990. Dispõe sobre a proteção do consumidor e dá outras providências. 1990.

CHORILLI, M.; MICHELIN, D. C.; SALGADO, H. R. N. Animais de laboratório: o camundongo. Revista de Ciências Farmacêuticas Básica e Aplicada, vol. 28, n. 1. 2007.

COMMUISSION OF THE EUROPEAN COMMUNITIES, SYNOPTIC. Document $N^{\circ} 7$, Draft of provisional list of monomers and additives used in the manufafacture of 
plastic materials and coatings intended to come into contact with foodstuffs. Document CS/PMJ2356, Brusels, Belgium, 15 May, 1994.

COMMISSION DIRECTIVE 2002/72/CE, 6 august 2002, relating to plastic materials and articles intended to come into contact with foodstuffs. Official Journal of the European Communities. P220/18. 2002.

ESTEVES, A. A.; ABRANTES, S. M. P.; BORGES, S. V.; SILVEIRA, M. G. Migração dos plastificantes adipatos e ftalatos de di-(2-etil-hexila) utilizados em filmes flexíveis de poli (cloreto de vinila) PVC que acondicionam alimentos gordurosos. Revista Higiene Alimentar, v. 20 n¹39, Março de 2006.

FLORES, A. V.; RIBEIRO, J. N.; NEVES, A. A.; QUEIROZ, E. L. R. Organoclorados: um problema de saúde pública. Ambiente \& Sociedade. Vol. VII nº 2 jul./dez. 2004

FOOD AND DRUG ADMINISTRATION. Plastics and the microwave. Disponível em: <http://www.fda.gov/fdac/features/2002/602_plastuc,html>. Acesso em: 10 de dezembro de 2008.

GIUST, J. A.; SPIPELT, C.T.; ANDERSON, B. K.; DEIS, D. A.; HINDER, J.D. Journal of Agriculture and Food Chemistry. V.38, p. 415-418, 1990.

LAU, O. W.; WONG, S.K. Contamination in food from packaging material. Journal of Chromatography A, v. 882, n. 1-2, p. 255.279, 2000.

MELO, Nathália Ramos de. Migração de plastificantes e avaliação de propriedades mecânicas de filmes de poli (cloreto de vinila) para alimentos. Tese (doutorado) Universidade Federal de Viçosa, MG, 2007.

NUNES, Luciano R. (org). Tecnologia do PVC. São Paulo: ProEditores / Braskem, 2002. 400p.

NUNES, M. V.; TAJARA, E. H. Efeitos tardios dos praguicidas organoclorados no homem. Revista Saúde Pública. Vol. 32 n 4, São Paulo, agosto de 1998.

PADULA, M. Migração de componentes da embalagem para alimentos: contaminação organolépica. Informativo CETEA, Campinas, v.7, n.5, p.9-11, set./out. 1995.

SANTOS, A. M. M. M.; GIMENEZ, L. C. P. Hiper e supermercados no Brasil. Elaboração: Gerência Setorial de Comércio e serviços. Dezembro de 1998. http://www.bndes.gov.br/conhecimento/relato/hiperm3.pdf. Acesso dia: 21/03/2009

SARANTOPOULOS, C. I. G. L.; OLIVEIRA, L. M.; PADULA, M.; COLTRO, L.; ALVES, R. M. V.; GARCIA, E. E. C. Embalagens plásticas flexíveis: principais polímeros e avaliação de propriedades. Campinas: CETEA/ITAL, 2002. 267p.

SOUZA, M. L.; CORIO, P.; TEMPERINI, M. L. A. Análise de plastificantes em filmes comerciais de PVC esticáveis por espectroscopia vibracional. Instituto de Química, Universidade de São Paulo, 2003. 
U. S. DEPARTMENT OF HEALTH AND HUMAN SERVICES. PUBLIC HEALTH SERVICE - AGENCY FOR TOXICITY SUBSTANCES AND DISEASE REGISTRY. Toxicological profile for di-(2-ethylhexyl) phthalate, 1993.

http://www.ibge.gov.br/home/estatistica/populacao/condicaodevida/pof/2002analise/d efaulttab.shtm - Acesso em: 13/10/2008

http://www.sidra.ibge.gov.br/bda/orcfam/default.asp - Acesso em: 13/10/2008 